\title{
Human somatosensory evoked responses: Effects of attention and distraction on early components
}

\author{
ROBERT A. LAVINE, MONTE S. BUCHSBAUM, and GAIL SCHECHTER \\ Section on Clinical Psychophysiology, Biological Psychiatry Branch \\ National Institute of Mental Health, Bethesda, Maryland 20205
}

\begin{abstract}
Previous studies in man have reported increases in the amplitude of late secondary evoked potential components, but not of early primary components, with attention. In this study, somatosensory evoked potentials were recorded over somatosensory cortex in normal volunteers while they were counting stimuli and while they were doing mental arithmetic. A positive wave (P30) recorded over the postcentral gyrus was found to be enhanced when subjects attended to the stimuli. This suggests that differential processing of attended stimuli may begin either prior to or at the level of primary sensory cortex.
\end{abstract}

Attention involves the selection of information from some modality or source and the relative rejection of other concurrent information. Neural facilitation or inhibition associated with this process could occur at any level, from the more peripheral synapses of the afferent pathway (as by corticofugal gating mechanisms) to various stages of cortical processing (Hernandez-Peon, 1966; Hillman \& Wall, 1969; Sokolov, 1963; Wall, 1967). Averaged evoked potentials (EPs) have been used to evaluate these possibilities. Generally, directing attention toward a sensory input has been found to increase the amplitude of later components of the EP, which are thought to represent intracortical events (Naatanen, 1975; Regan, 1972), probably originating in association cortex (Picton \& Hillyard, 1974). The negative component at $110-140 \mathrm{msec}$, termed N120, has been found to be particularly sensitive to attentional effects in several modalities (Hillyard, Picton, \& Regan, 1978). In contrast, earlier components $(<80 \mathrm{msec})$, in those few studies in which they have been measured, appeared unchanged (Picton \& Hillyard, 1974; Velasco, Velasco, Machado, \& Olvera, 1973). The interpretation of these results is hindered, however, by the difficulty or impossibility of recording a primary evoked potential, representing the postsynaptic responses of primary sensory cortex, to auditory or visual stimuli (Picton, Hillyard, Krausz, \& Galambos, 1974; Goff, Allison, Lyons, Fisher, \& Conte, 1977).

This study takes advantage of the general agreement that a positive wave (P30) recorded over the human somatic sensory cortex (postcentral gyrus) and peaking approximately $30 \mathrm{msec}$ after peripheral nerve stimulation at contralateral wrist or fingers represents the primary evoked potential (Allison, Goff, Abrahamian, \& Rosner, 1963; Celesia, 1979; Cracco, 1972; Goff, Matsumiya, Allison, \& Goff, 1977; Goff,
Rosner, \& Allison, 1962). An increase in P30, with attention directed toward somatosensory input, would indicate that modulation of afferent input occurs either prior to or at the first cortical level. Information derived from later peaks could be related to intracortical processing, probably in association cortex.

\section{METHODS}

Nineteen paid normal volunteers $(8$ men and 11 women, aged 18 to 37 years) served as subjects. Stimuli were applied to the digital nerves via two ring electrodes placed on the middle (second) finger of the left hand. The skin was prepared by being rubbed with Redux (Hewlett Packard paste) to reduce electrode resistance to about $7 \mathrm{k} \Omega$. Stimuli were single biphasic pulses of $1 \mathrm{msec}$ duration from a computer-controlled constant-current amplifier. The rectangular biphasic waveform further reduced any stimulus artifact in the recording. Threshold stimulus intensities were determined; for each subject, several series of ascending and descending stimuli were presented until reliable thresholds were obtained. Over the 19 subjects, mean threshold $=.93 \mathrm{~mA} ; \mathrm{SD}=.39$. Two stimulus intensities were used for ER recording, a low intensity, $.25 \mathrm{~mA}$ above threshold, and a higher intensity, $1.25 \mathrm{~mA}$ above threshold. The subjects perceived the stimuli as weak and distinct taps or flicks. For each run, 64 low- and 64 high-intensity stimuli were presented, at intervals of $1.0 \mathrm{sec}$, intermixed in a constrained random series; each stimulus was preceded by the low and high intensity an equal number of times. A grounded metal armband was placed around the left forearm to diminish stimulus artifact.

The EEG was recorded from the scalp over the right postcentral gyrus area $(7 \mathrm{~cm}$ lateral and $2 \mathrm{~cm}$ posterior to the vertex) referred to the earlobe on the same side, amplified (flat passband 1-110 Hz), and sampled at 2-msec intervals for $512 \mathrm{msec}$ Electrode impedance was $10 \mathrm{k} \Omega$ or less. Responses to high and low intensities were averaged separately on-line. EPs were first detrended, using linear regression, and then digitally filtered to remove frequencies below $3 \mathrm{~Hz}$, at $59-61 \mathrm{~Hz}$ and above $110 \mathrm{~Hz}$. Digital filtering was accomplished by using the Fourier transform of the EP. Complex coefficients of frequencies to be removed were set to 0 , and the inverse transform was then taken to resynthesize the signal. 
Subjects were seated comfortably in a quiet room and asked to close their eyes and relax. Each subject recieved both an attention-condition ("A," count the number of times a stimulus of any intensity is followed by a stimulus of the same intensity) and a distraction condition ("D," subtract 7s serially from 1,000 or 2,000 while disregarding the stimuli). The subjects were asked to report the resulting stimulus count or remainder at the end of each run. Thirteen of the 19 subjects reported stimulus counts within four counts of the correct number (32). The order of runs was balanced (A-D-D-A-D-A-A-D for 9 subjects, D-A-A-D-A-DD-A for the other 10 subjects).

For each subject, EPs to four A runs were averaged together and ERs to four D runs were averaged together to produce grandaverage EPs to 256 stimuli for each intensity-condition combination. Since EPs to higher intensity stimuli exhibited more distinct peaks, only these were analyzed here. These EPs were first examined for the presence of P30, a positive peak between 26 and $36 \mathrm{msec}$. This latency range represents a natural cluster in our data and is almost identical to the range reported (Celesia, 1979) for the early positive peak recorded directly from human somatosensory cortex upon median nerve stimulation. Since our data is based on finger stimulation, for this comparison, we added $2.5 \mathrm{msec}$ to Celesia's latencies for the conduction time from finger to median nerve (Smorto \& Basmajian, 1972). Fourteen of the 19 subjects met this criterion for $\mathrm{P} 30$ for both attention and mental arithmetic conditions and only these were studied further (Figure 1). Individuals were selected prior to any measurement or comparison of peak amplitude and without knowledge of task performance to avoid subjective bias. The following peaks were also measured in these 14 subjects: P15 (between 10 and $18 \mathrm{msec}$ ), P50 (a positive peak between 35 and $55 \mathrm{msec}$ ), and N70 (a negative peak between 50 and $106 \mathrm{msec}$ ). Peaks were measured from a baseline consisting of the mean amplitude of the entire 512-msec recording

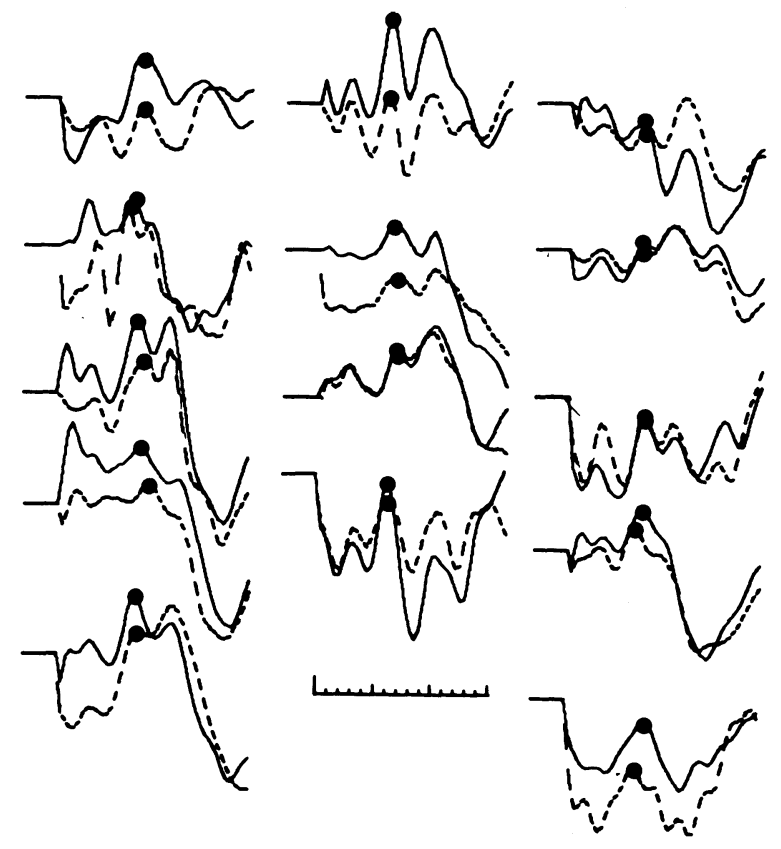

Figure 1. Evoked responses to higher intensity stimuli in 14 subjects while counting stimulus pairs (attention condition, solid lines) or doing mental arithmetic (distraction condition, dotted lines). Large dots indicate the P30 component. Curves are aligned on the mean value over the entire 500 -msec epoch, indicated by the flat initial line segment. Time scale begins at stimulus presentation with 5-msec small divisions and 25-msec large divisions. epoch. P30 was also measured from a baseline using the mean value from 5 to $75 \mathrm{msec}$. In testing for possible amplitude differences between the attention and distraction conditions, each subject served as his own control and the two-tailed paired $t$ test was used.

\section{RESULTS}

For peak P30, the amplitude for the attention condition was significantly greater $(p<.01)$ than the amplitude for the distraction condition (Table 1). This occurs whether the peak is measured relative to the mean of the entire 512-msec recording epoch or relative to a local $(5-75 \mathrm{msec})$ baseline. Using the latter baseline, $11 / 14$ subjects showed attentional enhancement of amplitude. A peak-to-peak measure, P30-N70, also showed a significant difference $(p<.02)$ in the same direction. Thus, P30 was increased during the attention condition whether measured from either baseline or from the succeeding N70 peak. No significant differences between conditions for peaks P15, P50, and N70 were found; nor were significant differences in peak latency found.

\section{DISCUSSION}

These results for $\mathrm{P} 30$ suggest that in our attention condition, as compared with our distraction condition, somatosensory input was enhanced or disinhibited at or prior to the postsynaptic response of primary somatosensory cortex. The relatively smaller and not statistically significant effect on the P15 peak, which is thought to represent activity of either the VPL thalamic relay nucleus (Allison et al., 1963; Cracco, 1972; Goff et al., 1962, 1977) or of lower levels of the somatosensory pathway (Celesia, 1979), suggests, first, that control of peripheral nerve excitation was adequately maintained and, second, that modification of input did not occur at subcortical levels of the classical afferent pathway.

Similarly, Picton and his co-workers found no changes during auditory attention in human cochlear nerve (Picton, Hillyard, Galambos, \& Schiff, 1971) or in components of the EP attributed to the brainstem auditory pathway (Picton \& Hillyard, 1974). The present experiment was designed to compare somatosensory attention with distraction rather than to study attention specifically directed to one modality or source compared with others (selective attention). Thus, like the studies of Picton and Hillyard (1974) and Schechter and Buchsbaum (1973) in the auditory and visual modalities, which were designed rather similarly, a modality-nonspecific effect, such as arousal difference, could contribute to our differences between conditions (see review by Naatanen, 1975). However, a major contribution from nonspecific arousal and associated EEG changes is rendered less likely by reports that P30 is unaffected by habituation or 
Table 1

Latency and Amplitude Measures in Peaks of Somatosensory Evoked Responses in Those Subjects with Distinct P30 and P70 Peaks for Both Attention (A) and Distraction (D) Conditions

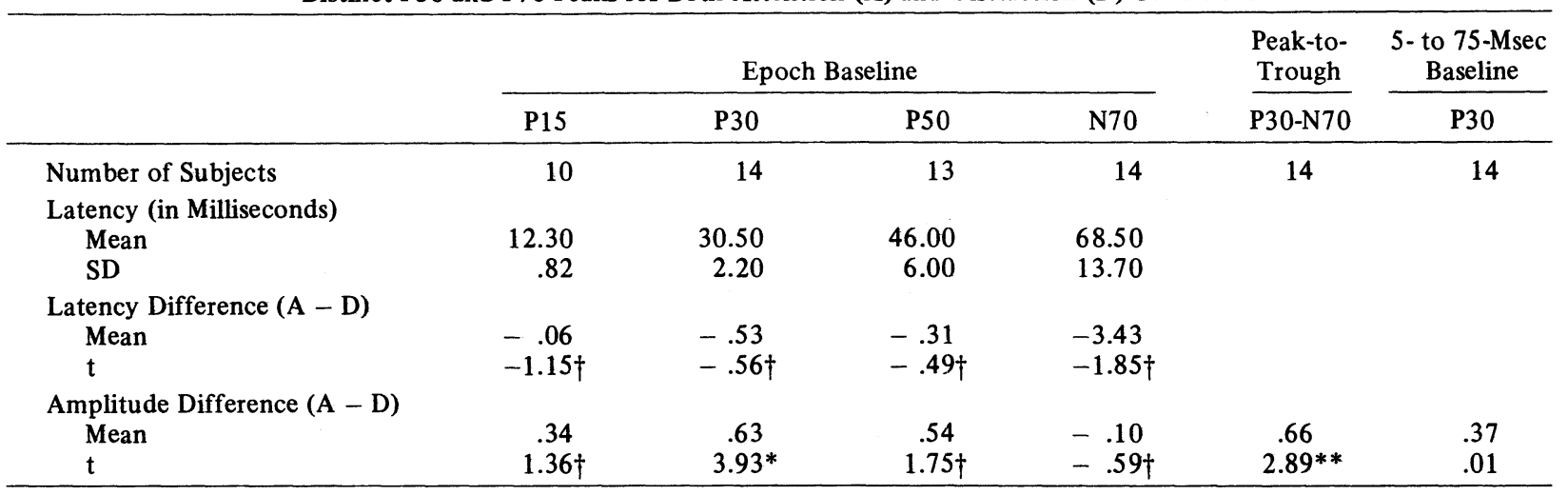

Note-For all measures, grand average EPs (256 trials averaged) to higher intensity stimuli were used. For calculating mean latency across subjects, latencies for $A$ and $D$ conditions were averaged for each subject to give a single (mean) latency value for each peak. For latency and amplitude differences, peak measures for the $D$ condition were subtracted from those for the $A$ condition for each subject, and a t test (two-tailed) on paired measurements was performed. $\quad{ }^{*} p<.01 . \quad{ }^{* *} p<.02 . \quad$ †Nonsignificant.

novelty (Velasco et al., 1973) and that the amplitude of the somatosensory EP is essentially independent of the amplitude and other parameters of the associated EEG (Salamy, 1974; Shagass, Overton, Bartolucci, \& Straumanis, 1971). Although Picton and Hillyard showed significant differences between attention and distraction conditions for later components attributed to association areas of cerebral cortex, no component corresponding to the primary auditory EP was identified by these or other authors. Picton and Hillyard did find a difference at the $\mathrm{p}<.05$ level for component $\mathrm{Na}$, which they suggest may derive from thalamic activity, but did not treat this finding as significant in view of the number of statistical comparisons performed. Experiments showing no difference in somatosensory P30 for attention compared with other conditions (Velasco et al., 1973) differed from ours in utilizing significantly greater stimulus intensities, in stimulating the entire median nerve as opposed to our more localized stimulation, in not balancing the order of presentation of conditions, and, perhaps most important for these small early components, in not applying rigid latency criteria for peak presence (Velasco et al., 1973). The finding by Desmedt and Robertson (1977) of no selective attention effect on their P45 is consistent with our P50 results, but they did not specifically assess P30 although it appears in their Figure 1.

The importance of P30 is also suggested by the observation that although data analysis was performed only on subjects who met a physiological criterion-the presence of P30-these subjects also demonstrated superior psychophysical performance. Thirteen of the 14 subjects selected on the basis of P30 reported stimulus counts within four counts of the correct count of 32 . The five subjects who did not meet the P30 criterion were all more deviant from the correct count.
Slow, negative-going shifts or baseline changes due to late components seem an unlikely source for our experimental effect. First, low-frequency components below $3 \mathrm{~Hz}$ were eliminated by detrending and digital filtering prior to any data analysis. Second, we obtained similar results when P30 was measured relative to N70, a peak-to-peak measure that has been shown to increase as a power function of stimulus intensity (Franzen \& Offenloch, 1969). Third, if a baseline shift were solely responsible for our P30 effect, a similar amplitude charge should have been seen with all early components. Lastly, similar results were obtained with the 5- to $75-\mathrm{msec}$ baseline, a technique which yielded slightly smaller, but more uniform, attentional effects across the subjects.

One possible physiological basis for a P30-attentional effect is suggested by animal experiments showing that electrical stimulation of a part of the thalamic reticular nucleus is capable of inhibiting the primary cortical evoked potential to somatosensory stimuli; the frontal cortex was proposed as the site governing this modality-specific control of cortical response (Yingling \& Skinner, 1976).

Our results indicate that attentional processes are capable of modulating incoming somatosensory information as early as the first cortical synapses. Whether our P30 changes represent orientation of the CNS toward processing external stimuli suppression of response to external stimuli during internal tasks (e.g., mental arithmetic) or the first stage of selective attention remains to be resolved by making further multitask comparisons.

\section{REFERENCES}

Allison, T., Goff, W. R., Abrahamian, H. A., \& Rosner, B. S. The effects of barbiturate anesthesia upon human somatosensory evoked responses. Electroencephalography and Clinical Neurophysiology, 1963, 24, 68-75. 
Cracco, R. Q. The initial positive potential of the human scalprecorded somatosensory evoked response. Electroencephalography and Clinical Neurophysiology, 1972, 32, 623-629.

Celesia, G. C. Somatosensory evoked potentials recorded directly from human thalamus and Sm I cortical area. Archives of Neurology, 1979, 36, 399-405.

Desmedt, J. E., \& Robertson, D. Differential enhancement of early and late components of the cerebral somatosensory evoked potentials during forced-paced cognitive tasks in man. Journal of Physiology, 1977, 271, 761-782.

Franzen, O., \& OfFenloch, K. Evoked response correlates of psychophysical magnitude estimates for tactile stimulation in man. Experimental Brain Research, 1969, 8, 1-18.

Goff, W. R., Allison, T., Lyons, W., Fisher, T. C., \& ConTE, R. Origins of short latency evoked potentials in man. In J. E. Desmedt (Ed.), Progress in clinical neurophysiology (Vol. 2). Basel: Karger, 1977.

Goff, G. D., Matsumiya, Y., Allison, T., \& Goff, W. R. The scalp topography of human somatosensory and auditory evoked potentials. Electroencephalography and Clinical Neurophysiology, 1977, 42, 57-76.

Goff, W. R., Rosner, B. S., \& Allison, T. Distribution of cerebral somatosensory evoked responses in normal man. Electroencephalography and Clinical Neurophysiology, 1962, 14, 697-713.

He rnandez-Peon, R. In R. N. Russell (Ed.), Frontiers in physiological psychology. New York: Academic Press, 1966.

Hillman, P., \& Wall, P. D. Inhibitory and excitatory factors influencing the receptive fields of lamine 5 spinal cord cells. Experimental Brain Research, 1969, 9, 284-306.

Hillyard, S. A., Picton, T. W., \& Regan, D. Sensation, perception and attention: Analysis using ERPs. In E. Callaway, P. Tueting, \& S. H. Koslow (Eds.), Event related potentials in man. New York: Academic Press, 1978.

NaAtanen, R. Selective attention and evoked potentials in humans-a critical review. Biological Psychology, 1975, 2, 237307.

Picton, T. W., \& Hillyard, S. A. Human auditory evoked potentials. II. Effects of attention. Electroencephalography and Clinical Neurophysiology, 1974, 36, 191-199.
Picton, T. W., Hillyard, S. A., Galambos, R., \& Schiff, R. Human auditory attention: A central or peripheral process. Science, 1971, 173, 351-353.

Picton, T. W., Hillyard, S. A., Krausz, H. I., \& Galambos, R. Human auditory evoked potentials. I: Evaluation of components. Electroencephalography and Clinical Neurophysiology, 1974, 36, 179-190.

REGAN, D. Evoked potentials in psychology, sensory physiology, and clinical medicine. London: Chapman and Hall, 1972.

Salamy, A. Validity of neuroelectric variables in predicting the average evoked potential. Psychophysiology, 1974, 11, 361-371.

Schechter, G., \& Buchsbaum, M. S. The effects of attention stimulus intensity and individual differences on the average evoked response. Psychophysiology, 1973, 10, 392-400.

Shagass, C., Overton, D. A., Bartolucci, G., \& Straumanis, J. J. Effect of attention modification by television viewing on somatosensory evoked responses and recovery functions. Journal of Nervous and Mental Diseases, 1971, 152, 53-62.

Smorto, M. P., \& Basmajian, J. V. Electroencephalography and Clinical Neurophysiology, Baltimore: Williams \& Wilkins, 1972.

SoKoLov, E. N. Higher nervous functions: The orienting reflex. Annual Review of Physiology, 1963, 25, 545- 580.

Velasco, M., Velasco, F., Machado, J., \& Olvera, A. Effects of novelty, habituation, attention and distraction on the amplitude of the various components of the somatic evoked response. International Journal of Neurosciences, 1973, 5, 101111.

WALL, P. D. The laminar organization of dorsal horn and effects of descending impulses. Journal of Physiology, 1967, 188, 403423.

Yingling, C. D., \& Skinner, J. E. Selective regulation of thalamic sensory relay nuclei by nucleus reticularis thalami. Electroencephalography and Clinical Neurophysiology, 1976, 41, 476-482.

(Received for publication December 10, 1979; revision accepted March 15, 1980.) 